\title{
Caracterização química e bioquímica de sementes de Bauhinia variegata L.
}

Luciano S. Pinto1', Manoel Andrade Neto², Marco A. Bacarin ${ }^{3}$, Rolando R. Castellón', Tatiane S. Gadelha ${ }^{5}$, Carlos A. Gadelha ${ }^{5}$ \& Benildo S. Cavada ${ }^{4}$

\footnotetext{
1 Centro de Biotecnologia/UFPel, Laboratório de Biologia Celular e Molecular Vegetal, Campus Universitário s/n CEP 96010- 900, CP 354, Pelotas, RS. E-mail: Is pinto@hotmail.com (Foto)

2 Departamento de Química Orgânica e Inorgânica UFC

${ }^{3}$ Departamento de Botânica/Laboratório de Metabolismo Vegetal/UFPel.

${ }_{4}^{4}$ BioMol-Lab, Departamento de Bioquímica e Biologia Molecular UFC, Campus do Pici s/n, CEP 60451-970. Fortaleza, Ce. Fone: (85) 4008-9818. E-mail: bscavada@ufc.br

${ }^{5}$ Departamento de Bioquímica, UFPB. Fone: (83) 216-7436. E-amil: santigadelha@uol.com.br
}

Protocolo $144-7 / 10 / 2002$ - Aprovado em 14/1/2005

\begin{abstract}
Resumo: Sementes quiescentes de Bauhinia variegata foram submetidas a caracterização bioquímica, por meio de análise elementar, fracionamento de proteínas e atividade hemaglutinante. A análise elementar mostrou grande quantidade de proteína total e de lipídeos, com 29,41 e $14,89 \%$, respectivamente. O ácido linoléico foi o mais encontrado na constituição lipídica das sementes e a composição mineral ficou dentro de níveis aceitáveis para o consumo humano. As diferentes frações protéicas (albuminas, globulinas, prolaminas, glutelinas ácidas e básicas) apresentaram atividade hemaglutinante contra hemácias tratadas e não-tratadas com enzimas proteolíticas, mas a maior atividade hemaglutinante específica foi evidenciada na fração globulínica; já nas frações glutelinas ácidas e albuminas, esta atividade é maior quando se utilizam hemácias de coelho previamente tratadas com tripsina e papaína, respectivamente. Assim, por apresentarem alto valor energético, as sementes de Bauhinia variegata são uma possível fonte opcional na alimentação.
\end{abstract}

Palavras-chave: leguminosa, nutrição humana, lipídeos, proteínas, carboidratos

\section{Chemical and biochemical characterization of Bauhinia variegata L. seeds}

\begin{abstract}
Seeds of Bauhinia variegata were submitted to biochemical characterization through elementary analysis, protein fractioning and hemaglutinanting activity. The elementary analysis of seed showed high protein and lipid contents, with 29.41 and $14.89 \%$, respectively. The linolenic acid was found in the lipidic constitution of the seeds and the mineral composition remained with in acceptable levels for the human consumption. The specific hemaglutinanting activity from different fractions of proteins (albumin, globulin, prolamin, glutelin acid and alkaline) demonstrated hemaglutinanting activity against native and enzyme treated rabbit erythrocytes. However, the fraction globulins showed the largest specific hemaglutinanting activity. Acid glutelin and albumin had a larger specific hemaglutinanting activity against tripisin-treated and papaintreated rabbit erythrocytes, respectively. Thus, for presenting high energy value, the seeds of Bauhinia variegata are an optional source for the feeding.
\end{abstract}

Key words: leguminous, human nutrition, lipids, proteins, carbohydrate

\section{INTRODUÇÃO}

Devido à necessidade de se incrementar a disponibilidade de proteínas para consumo humano e/ou animal, os estudos com sementes de espécies da família Leguminoseae têm sido intensificados (Penãte et al.,1988). Atualmente, os estudos de proteínas em sementes de plantas superiores se sobressaem, destacando-se as espécies da classe das Angiospermas, porém apenas algumas espécies do gênero Bauhinia estão sendo investigadas, limitando-se às suas propriedades hipoglicêmicas, apesar de serem descritas, também, como depurativas e diuréticas (Almeida, 1993). Esses relatos se tornam ainda mais escassos quando se trata de sementes de Bauhinia variegata. As espécies do gênero Bauhinia, pertencentes à família das 
leguminosas (Fabales: Caesalpinaceae) encontram-se nas zonas tropicais do mundo inteiro; no Brasil, as mais comuns são $B$. candicans e $B$. forficata, sendo $B$. variegata a mais cultivada entre as espécies exóticas; todas, no entanto são popularmente conhecidas como pata-de-vaca, algumas utilizadas em paisagismo, e outras como forrageiras (Braga, 1960). O conteúdo protéico em sementes de leguminosas, com exceção da soja e do amendoim, varia entre 18 e 32\% (Milner, 1972). A quantidade de proteínas é, na maioria das vezes, maior em leguminosas que em cereais. Apesar do conteúdo de reserva das sementes de leguminosas ser, em geral, mais elevado, suas proteínas são consideradas de baixo valor nutricional devido à deficiência em aminoácidos sulfurados e à presença de alguns fatores antinutricionais, como lectinas e inibidores de proteases (Korte, 1972; Grant et al., 1982). Fatores antinutricionais, como lectinas, são deletérios ou tóxicos aos animais e ao homem (Liener, 1994), necessitando ser removidos ou inativados por um pré-tratamento das sementes, antes do consumo na dieta, mas nem sempre se consegue uma eliminação eficaz desses compostos, principalmente se o cozimento não for realizado com eficiência (Korte, 1972). Este é um problema, sobretudo sério com relação às lectinas de semente, pois algumas são resistentes ao tratamento térmico, necessitando de um tempo maior ou de temperatura elevada para a degradação completa (Grant et al., 1982). Torna-se essencial que todas as fontes potenciais de alimento sejam examinadas quanto aos teores de lectinas e sua possível toxicidade (Grant et al., 1991).

A avaliação da qualidade nutritiva verdadeira em contraste com o índice nutritivo analisado em sementes potencialmente utilizáveis como fonte nutritiva, seria de interesse econômico das indústrias de grãos e de criação de animais domésticos para consumo, já que são fontes alternativas para alimentação. A quantidade de fatores antinutricionais em legumes varia entre e dentro de uma mesma espécie (Alitor et al., 1994; Gatel, 1994). Estabeleceu-se que a ingestão de uma quantidade significativa desses fatores por aves domésticas ou por porcos reduz o ganho do peso e aumenta o consumo (Batterham et al., 1993; Igbasan \& Guenter, 1996). Os mecanismos pelas quais os fatores antinutricionais induzem seus efeitos negativos, não foram ainda compreendidos claramente, mas é consenso que interferem nas funções digestivas normais (van Kempen, 1993; Gatel, 1994).

Assim, buscou-se com este estudo verificar a presença de lectinas nas sementes de Bauhinia variegata e a possível utilização dessas sementes como fonte protéica na alimentação humana e/ou animal.

\section{MATERIAL E MÉTODOS}

\section{Material vegetal}

Sementes quiescentes de B.variegata, coletadas na cidade de Americana, SP, foram levadas ao Laboratório de Moléculas Biologicamente Ativas (BioMol - Lab) do Departamento de Bioquímica da Universidade Federal do Ceará, onde foram trituradas em moinho elétrico do tipo Willey (acoplado com peneira de $60 \mathrm{mesh}$ ). A farinha foi submetida a análise elementar e fracionamento de proteínas.

\section{Composição mínima}

A determinação do teor de umidade das sementes foi conduzida colocando-se $1,0 \mathrm{~g}$ do material fresco em pesa-filtros, previamente tarados, em estufa a $110^{\circ} \mathrm{C}$, até apresentarem massa constante. $\mathrm{O}$ teor de umidade foi calculado pela diferença entre as massas inicial e final das amostras, sendo este valor expresso em porcentagem.

Para o teor de cinzas das sementes, amostras de $1 \mathrm{~g}$ de material seco permaneceram durante $4 \mathrm{~h}$ em mufla, a $600{ }^{\circ} \mathrm{C}$; posteriormente, as amostras foram transferidas para um dessecador e, após atingirem a temperatura ambiente, tiveram suas massas novamente aferidas, para verificação do teor de cinzas, que foi expresso em porcentagem.

O nitrogênio total das farinhas foi analisado pelo método de semi-micro Kjeldhal (Hiller, 1948). O teor de proteínas totais foi calculado pela multiplicação do valor encontrado para nitrogênio total pelo fator 6,25 .

\section{Composição de minerais}

A composição mineral das sementes foi determinada de acordo com a metodologia descrita por Silva (1990). Amostras em triplicata sofreram digestão ácida e os teores de cobre, zinco, manganês, ferro, potássio, cálcio e magnésio, foram analisados em espectrofotômetro de absorção atômica. O fósforo foi analisado em espectofotômetro de emissão e o sódio em fotômetro de chama.

\section{Carboidratos solúveis e insolúveis}

O teor de fibra bruta (carboidratos insolúveis) das sementes foi estimado segundo técnica descrita por Silva (1990). Para a extração de carboidrato utilizou-se a técnica descrita por McCready et al. (1950), enquanto a dosagem dos carboidratos solúveis totais foi conduzida de acordo com a técnica de Clegg (1956) e o teor de açúcares redutores foi estimado utilizandose alíquotas de $30 \mu \mathrm{L}$ do extrato evaporado. Este volume foi completado para 1,0 mL com água ultra pura estéril; posteriormente, adicionou-se mais $1,0 \mathrm{~mL}$ de reagente do Nelson (solução de molibdato de amônio + ácido sulfúrico concentrado + arseniato dibásico de sódio), em que a solução resultante foi fervida durante $20 \mathrm{~min}$; após resfriamento em água corrente, 1,0 mL de solução arsenomobilídica e 7,0 mL de água ultra pura estéril foram adicionados à mistura reagente, cuja leitura feita em espectrofotômetro a um comprimento de onda $540 \mathrm{~nm}$ (Nelson, 1944). O teor dos aminoácidos solúveis totais foi analisado a partir de alíquotas de $50 \mu \mathrm{L}$, provenientes do extrato obtido para a quantificação de carboidratos solúveis totais. Alíquotas foram colocadas em tubos rosqueáveis e seu volume completado para 2,0 mL com água ultra pura estéril; depois se lhe adicionou $1,5 \mathrm{~mL}$ do reagente de ninhidrina (mistura 1:1 de $\mathrm{SnCl}_{2}$ em tampão citrato + ninhidrina em metil celosolve), após agitação vigorosa, o material foi fervido por $20 \mathrm{~min}$, resfriado em água corrente e em seguida 8,0 $\mathrm{mL}$ de etanol $50 \%$ foram adicionados, enquanto o material resultante após agitação, foi mantido a temperatura ambiente pelo tempo de 10 min e a absorbância determinada a 570 nm, utilizando-se como padrão uma solução estoque 1,0 mM de aminoácidos (Bruening, 1970). 


\section{Lipídeos e ácidos graxos}

Determinaram-se os lipídeos totais conforme a técnica descrita por Triebold (1946) em que o éter foi substituído por hexano. O teor de ácidos graxos foi determinado segundo a técnica modificada de Matos (1988), em triplicata, utilizandose aproximadamente $2,0 \mathrm{~g}$ do extrato lipídico dissolvido em 60 $\mathrm{mL}$ de solução 0,6 $\mathrm{M}$ de $\mathrm{KOH}$ em etanol.

A mistura reacional foi submetida a refluxo durante $6 \mathrm{~h}$, seguindo-se a adição de $20 \mathrm{~mL}$ de água destilada, para a obtenção do material insaponificável através de extração com 3 porções de hexano. A porção hexânica foi lavada com água ultra pura estéril, secada com $\mathrm{Na}_{2} \mathrm{SO}_{4}$ anidro, filtrada e concentrada sob vácuo em rotavapor. A fração aquosa foi acidificada com $\mathrm{HCl}$ até $\mathrm{pH}$ 2,0; subseqüentemente, a mistura foi acondicionada em funil de separação e lavada com n-hexano para obtenção dos ácidos graxos livres. A solução hexânica contendo os ácidos graxos livres, foi lavada com água ultrapura estéril, filtrada em $\mathrm{Na}_{2} \mathrm{SO}_{4}$ anidro e concentrada em rotavapor. Os ácidos graxos livres foram depois metilados com diazometano para obtenção dos seus respectivos ésteres metílicos (Matos et al., 1992).

\section{Proteínas solúveis}

O teor de proteínas solúveis totais presente nas diferentes frações protéicas na farinha de sementes de B.variegata foi determinado obedecendo a metodologia descrita por Bradford (1976), utilizando-se albumina sérica bovina (BSA) como padrão.

\section{Fracionamento de proteínas das sementes}

As sementes de B.variegata foram submetidas a extração e fracionamento de proteínas, de acordo com sua solubilidade (globulinas, prolaminas, albuminas, glutelinas ácidas e básicas) (Osborne, 1924); inicialmente, 5,0 g das sementes moídas foram deixados em contato com uma solução salina $(\mathrm{NaCl} 0,5 \mathrm{M})$, na proporção 1:10 (m:v), com agitação constante, durante $3 \mathrm{~h}$, em temperatura ambiente. Este material foi centrifugado a 10.000 rpm, durante $30 \mathrm{~min}$, filtrado em papel-filtro e o resíduo reextraído nas mesmas condições, por 1,0 h. O sobrenadante obtido foi dialisado com água ultrapura estéril, por $48 \mathrm{~h}$, e centrifugado; o novo sobrenadante continha a fração albumina e o precipitado, depois de ressuspenso, em $15 \mathrm{~mL}$ de $\mathrm{NaCl} 0,5 \mathrm{M}$, constituiu a fração globulínica; para obtenção da fração protéica de prolaminas, o resíduo da extração inicial com $\mathrm{NaCl} 0,5 \mathrm{M}$ foi submetido a extração com etanol $70 \% \mathrm{a}-4{ }^{\circ} \mathrm{C}$ por $1 \mathrm{~h}$ e, após centrifugação, o sobrenadante continha as prolaminas e o novo resíduo foi extraído com $\mathrm{HCl} 0,1 \mathrm{M}$, pelo tempo de $1,0 \mathrm{~h}$, filtrado e o sobrenadante dialisado, durante $48 \mathrm{~h}$, para obtenção da fração glutelinas ácidas. O resíduo submetido a contato com $\mathrm{NaOH} 0,1 \mathrm{M}$ por $1 \mathrm{~h}$ foi centrifugado nas mesmas condições anteriores para a obtenção da fração glutelinas básicas; enfim, alíquotas dessas frações protéicas foram submetidas a ensaios de hemaglutinação e dosagem de proteínas, antes de serem liofilizadas.

\section{Ensaio de atividade hemaglutinante}

A determinação da atividade hemaglutinante nos diferentes extratos protéicos, foi realizada utilizando-se suspensões de hemácias de coelho a $2 \%$, nativas e tratadas com enzimas proteolíticas (tripsina e papaína). O título de hemaglutinação, expresso em Unidades de Hemaglutinação (UH) foi determinado como sendo o inverso da maior diluição ainda capaz de apresentar aglutinação visível a olho nu (Moreira \& Perrone, 1977).

\section{RESULTADOS E DISCUSSÃO}

Os valores encontrados para a composição mínima (umidade e cinzas), carboidratos solúveis e insolúveis, proteínas e lipídeos encontrados nas sementes de $B$. variegata, são mostrados na Tabela 1. A porcentagem de umidade das sementes de $B$. variegata foi $3,71 \%$, inferior, portanto, à encontrada para B. forficata, $13,68 \%$ (Braga, 1960), B. purpurea, 8,4\%, B. racemosa, 9,69\%, B. valhii, 13,64\% (Rajaram \& Janardhanan, 1991) e B. monandra, 11,2\% (Peñate et al., 1988). Este baixo teor de umidade pode levar a uma redução no custo de armazenamento das sementes, em razão de menor tempo de secagem e também menor suscetibilidade ao ataque de microrganismos. O teor de cinzas em $B$. variegata foi de $4,41 \%$, valor parecido com o encontrado por Peñate et al. (1988) para B. monandra, 4,6\%; contudo, superior aos valores obtidos para B. purpurea, 3,69\%, B. racemosa, 2,46\% e B. valhlii, 3,96\% (Rajaram \& Janardhanan, 1991).

O teor de carboidratos solúveis totais nas sementes $(13,38 \%)$ foi relativamente baixo quando comparado com o de outras leguminosas, como Andira retusa (67,7\%) e Dalbergia miscolobium (75,0\%), mas semelhante aos valores citados para Lonchocarpus araripensis (12,5\%) e Vatairea macrocarpa $(13,1 \%)$ (Sousa, 1997). O teor de açúcares redutores das sementes foi de $4,46 \%$ e o de amido chegou a $20,08 \%$ do total de carboidratos. Os carboidratos insolúveis (fibra bruta) foram de 9,26\%, mostrando-se superiores aos valores obtidos para B. purpurea, 4,66\%, B. racemosa, 6,46\% e B. vahlii, 6,5\% (Rajaram \& Janardhanan, 1991).

Altos teores de proteínas e lipídeos totais, 29,29 e 16,41\%, respectivamente, foram evidenciados nas sementes de Bauhinia variegata; referidos dados são superiores aos encontrados para $B$. forficata, $19,69 \%$ de proteína bruta e $5,89 \%$ de lipídeos (Braga, 1960), B. racemosa, 16,84\% de proteínas e $5,87 \%$ de lipídeos (Rajaram \& Janardhanan, 1991). Quando comparado o teor de lipídeos com B. petersiana, 17,6\%, estes são inferiores; porém Rajaram \& Janardhanan (1991) encontraram, para B. purpurea, teores de proteína $(25,63 \%) \mathrm{e}$ de lipídeos (14\%) semelhantes; já $B$. monandra apresenta teores de proteína bruta e lipídeos superiores, chegando a 32,7 e 18,9\%, respectivamente (Peñate et al., 1988; Ketshajwang et al., 1998). Em comparação com algumas espécies do gênero Bauhinia e outras leguminosas como Vigna unguiculata, utilizadas na alimentação humana, $B$. variegata mostra ótimo valor energético, uma vez que seus teores de proteína total e lipídeos são maiores que os encontrados nas cultivares de Vigna, que apresentam valores máximos de proteína próximos a 23,60\% e de lipídeos a 3,08\% (Araújo, 1997). Apesar do elevado valor energético, a maioria dos autores destaca a baixa quantidade de aminoácidos sulfurados nas proteínas dessas leguminosas, o que diminui seu valor nutritivo (Peñate et al., 1988; Rajaram \& Janardhanan, 1991). 
Tabela 1. Teores de umidade, proteínas, lipídeos, cinzas, carboidratos, açúcares redutores e fibras em sementes de B.variegata com base na massa seca

\begin{tabular}{lc}
\hline Constituinte & Teor na amostra (\%) \\
\hline Umidade & 3,71 \\
Cinza & 4,41 \\
Açúcares redutores & 4,46 \\
Fibra bruta & 9,26 \\
Carboidratos solúveis totais & 13,38 \\
Lipídios & 16,41 \\
Amido & 19,08 \\
Proteína & $29,29 *$ \\
\hline *Nitrogênio total x 6,25 &
\end{tabular}

Da mesma forma que em B. racemosa (Mohan \& Janardhanan, 1994) os ácido palmítico e linoléico se acumularam mais na constituição lipídica das sementes de Bauhinia variegata (Tabela 2) o que, do ponto de vista nutricional, é importante, desde que o ácido linoléico seja um ácido graxo essencial muito requerido na dieta de mamíferos; além disto, a alta porcentagem de ácidos graxos insaturados nessas farinhas viabiliza a sua utilização como fonte alimentícia saudável. O teor de lipídeos insaponificáveis nas sementes foi $0,15 \%$ e de saponificáveis, $15,73 \%$

Tabela 2. Porcentagem de ácidos graxos dos lipídeos das sementes de Bauhinia variegata

\begin{tabular}{lc}
\hline Ácidos graxos & $(\%)$ \\
\hline Ácido palmítico & 19,69 \\
Ácido linoléico & 56,98 \\
Ácido esteárico & 13,98 \\
Ácido eicosanóico & 1,08 \\
\hline
\end{tabular}

Os teores dos minerais analisados (Tabela 3 ) foram bastante semelhantes àqueles encontrados para $B$. purpurea, $B$. racemosa e $B$. valhlii, conforme descrito por Rajaram \& Janardhanan (1991); eles citam, ainda, que a composição mineral dessas sementes está dentro de níveis adequados para o consumo humano; apenas os níveis de cálcio das sementes de $B$. variegata, foram menores que os de $B$. racemosa e $B$. valhlii.

O teor das frações protéicas albuminas, globulinas, prolaminas, glutelinas ácidas e básicas das sementes de $B$. variegata, está ilustrado na Tabela 4 . O teor da fração globulinas foi quantitativamente superior $(66,12 \%)$ ao das

Tabela 3. Composição de minerais das sementes de Bauhinia variegata

\begin{tabular}{lr}
\hline Mineral & $\mathrm{g} \mathrm{kg}^{-1}$ \\
\hline Fósforo & 2,5 \\
Potássio & 11,5 \\
Cálcio & 2,9 \\
Magnésio & 5,1 \\
Cobre & 1,4 \\
Zinco & 0,8 \\
Ferro & 1,3 \\
Manganês & - \\
\hline - Não detectado & \\
R. Bras. Eng. Agríc. Ambiental, Campina Grande, v.9, n.3, p.385-390, 2005
\end{tabular}

demais frações protéicas, cujos resultados atendem aos dados obtidos para B. purpurea e B. vahlii, em que globulinas também foram as principais proteínas encontradas nas sementes dessas espécies chegando, em $B$. purpúrea e juntamente com a fração albumínica, a perfazer $82 \%$ do teor de proteínas das sementes (Rajaram \& Janardhanan, 1991). Esses mesmos autores encontraram, ainda, predomínio da fração glutelinas, em $B$. racemosa e, mesmo não sendo a fração protéica predominante nas sementes de $B$. variegata, a fração glutelinas ácidas pode ser considerada alta para leguminosas, já que, normalmente, são encontradas em maior quantidades em outras famílias.

Tabela 4. Porcentagem de proteínas solúveis das frações protéicas da semente de $B$. variegata

\begin{tabular}{lccc}
\hline \multicolumn{1}{c}{ Fração protéica } & $\begin{array}{c}\text { Teor } \\
\left(\mathrm{mg} \mathrm{g}^{-1} \mathrm{MF}\right)\end{array}$ & Massa $(\mathrm{g})$ & $\begin{array}{c}\text { Massa } \\
(\%)\end{array}$ \\
\hline Prolaminas & 13,5 & 0,0193 & 1,71 \\
Glutelinas ácidas & 13,8 & 0,0248 & 2,19 \\
Albuminas & 13,1 & 0,1598 & 14,13 \\
Glutelinas básicas & 16,9 & 0,1793 & 15,85 \\
Globulinas & 146,1 & 0,7478 & 66,12 \\
\hline
\end{tabular}

A atividade hemaglutinante específica das diferentes frações protéicas (glutelinas ácidas e básicas, globulinas, albuminas e prolaminas) da farinha de sementes de B.variegata foi estudada como possível fator antinutricional. Os resultados dos ensaios de atividade hemaglutinante são apresentados na Tabela 5. Verificou-se que todas as frações apresentaram atividade hemaglutinante contra sangue de coelho normal ou tratado com enzimas proteolíticas (papaína e tripsina); no entanto, a fração globulinas apresentou a maior atividade hemaglutinante específica $\left(2242,84 \mathrm{UH} \mathrm{mg}^{-1}\right.$ proteína) observada para sangue de coelho tratado com papaína. A atividade

Tabela 5. Atividade hemaglutinante específica contra hemácias de coelho a $2 \%$ e teores de proteína solúveis nas frações protéicas de $B$. variegata

\begin{tabular}{|c|c|c|c|c|}
\hline Fração & Sangue & $\mathrm{UH}_{\mathrm{g} \mathrm{F}} \mathrm{F}^{-1(\mathrm{~A})}$ & $\mathrm{mg} \mathrm{P} \mathrm{GF}^{-1(\mathrm{~B})}$ & $\mathrm{UH} \mathrm{mg} \mathrm{P}^{-1(\mathrm{C})}$ \\
\hline \multirow{3}{*}{$\begin{array}{l}\text { Glutelinas } \\
\text { ácidas }\end{array}$} & Normal & 1280 & \multirow{3}{*}{13,8} & 92,75 \\
\hline & $\mathrm{c} /$ Tripsina & 10240 & & 742,03 \\
\hline & c/Papaína & 5120 & & 371,02 \\
\hline \multirow{3}{*}{$\begin{array}{l}\text { Glutelinas } \\
\text { básicas }\end{array}$} & Normal & 1280 & \multirow{3}{*}{16,9} & 75,74 \\
\hline & $\mathrm{c} /$ Tripsina & 5120 & & 302,96 \\
\hline & c/Papaína & 10240 & & 605,92 \\
\hline \multirow{3}{*}{ Globulinas } & Normal & 10240 & \multirow{3}{*}{146,1} & 70,09 \\
\hline & $\mathrm{c} /$ Tripsina & 81920 & & 560,71 \\
\hline & c/Papaína & 327680 & & 2242,84 \\
\hline \multirow{3}{*}{ Albuminas } & Normal & 1280 & \multirow{3}{*}{13,1} & 97,71 \\
\hline & $\mathrm{c} /$ Tripsina & 2560 & & 195,42 \\
\hline & c/Papaína & 10240 & & 781,68 \\
\hline \multirow{3}{*}{ Prolaminas } & Normal & 160 & \multirow{3}{*}{13,5} & 11,91 \\
\hline & $\mathrm{c} /$ Tripsina & 80 & & 5,93 \\
\hline & c/Papaína & 160 & & 11,91 \\
\hline
\end{tabular}

${ }^{\text {A}}$ Unidade hemaglutinante por grama de farinha

${ }^{\mathrm{B}}$ Miligrama de proteína por grama de farinha

${ }^{\mathrm{C}}$ Unidade hemagluitnante por miligrama de proteína 
hemaglutinante da fração prolaminas foi menos específica que a observada para as outras frações, não havendo diferença na atividade hemaglutinante entre o sangue tratado com papaína e o não tratado com as enzimas proteolíticas. Trabalhando com eritrócitos do sistema ABO humano, Rajaram \& Janardhanan (1991) encontraram atividade hemaglutinante específica na fração globulinas de $B$. vahlii contra sangue humano do grupo B. Nas frações albuminas e globulinas de $B$. purpurea, esses mesmos autores observaram atividade hemaglutinante contra todos os tipos sanguíneos humanos testados, mas não notaram o mesmo para as albuminas de $B$. racemosa quando testadas contra hemácias deste sistema. Apesar da atividade hema-glutinante ser considerada fator antinutricional por vários autores, geralmente é inibida quando as sementes são submetidas a altas temperaturas.

No Brasil, apesar deste gênero ser encontrado em praticamente todas as regiões, seu uso é restrito à medicina popular, sem notícias da sua utilização na alimentação humana; já na Índia, espécies deste gênero são empregadas por tribos na alimentação, tanto na forma in natura quanto cozidas (Mohan \& Janardhanan, 1994).

\section{CONCLUSÕES}

1. As sementes de Bauhinia variegata apresentam alto valor energético e níveis de minerais dentro dos padrões de outras leguminosas que são utilizadas na alimentação humana e/ou animal.

2. A análise das frações protéicas das sementes de Bauhinia variegata permitiu determinar a presença de pelo menos uma lectina.

3. Estudos detalhados sobre possíveis fatores tóxicos ou antinutricionais presentes nas referidas sementes devem ser realizados, portanto é necessário tomar cuidados no uso das mesmas como material alimentício.

\section{AGRADECIMENTOS}

Este trabalho foi desenvolvido com o apoio das seguintes instituições: CNPq, CAPES, FUNCAP, UFPEL, BNB, UFC, PADETEC. B.S. Cavada é Pesquisador Senior do CNPq. Agradecemos ainda a colaboração dos pesquisadores Rozilaine A.P.G. Faria e Celso Shiniti Nagano.

\section{LITERATURA CITADA}

Alitor, V.A.; Goodchild, A.V.; Abdel Monein, A.M. Nutritional and antinutritional characteristics of selected vicia genotypes. Animal Feed Science and Technology, Amsterdam, v.47, n.1-2, p.125-139, 1994.

Almeida, E.R. Plantas medicinais brasileiras, conhecimentos populares e científicos. São Paulo: Hemus Editora Ltda, 1993. $60 \mathrm{p}$.

Araújo, F.M.M.C. Caracterização bioquímica de sementes de cultivares de Caupi (Vigna unguiculata (L) Walp.) Fortaleza: UFC. 1997. 84p. Dissertação Mestrado
Batterham, E.S.; Saini, H.S.; Andersen, L.M.; Baigent, R.D. Tolerance of growing pigs to trypsin and chymotrypsin inhibitors in chickpeas (Cicer arietinum) and pigeonpeas (Cajanus cajan). Journal Science Food Agriculture, London, v.61, n.2, p.211-216. 1993.

Bradford, M.M. A rapid and sensitive method for the quantitation of microgram quantities of proteins utilizing the principle of protein-dye binding. Analytical Biochemistry, New York, v.72, n.1-2, p.248-254, 1976.

Braga, R. Plantas do nordeste especialmente do Ceará, 2.ed. Fortaleza: Imprensa Oficial, 1960. 425p.

Bruening, G.; Criggle, R.; Preiss, J.; Ruder, T.F. Biochemistry experiments. New York: John Wiley, 1970.314 p.

Clegg, K.M. The application of the anthrone reagent to the estimation of starch in cereals. Journal Science Food Agriculture, London, v.7, n.1, p.40-44, 1956.

Gatel, F. Protein quality of legume seeds for non-ruminant animals: A literature review. Animal Feed Science and Technology, Amsterdam, v.45, n.3-4, p.317-348, 1994.

Grant, G.; More, L.J.; McKenzie, N.H.; Dorward, P.M.; Stewart, J.C.; Telek, L.; Pusztai, A. A survey of the nutritional and haemagglutination properties of several tropical seeds. Livestock Research for Rural Development, Calli, v.3, n.3, p. 33-55, 1991.

Grant, G; More, L.J.; McKenzie, N.H.; Pusztai, A. The effect of heating on the haemagglutinating activity and nutritional properties of bean (Phaseolus vulgaris) seeds. Journal of Science Food and Agriculture, London, v.33, n.1, p.13241326, 1982.

Hiller, A.; Plazin, J.; Vanslyke, D.D. A study of conditions for Kjeldahl determination of nitrogen in proteins. Journal of Biology and Chemistry, Baltimore, v.176, n.3, p.1401-1420, 1948. Igbasan, F.A.; Guenter, W. The enhancement of nutritive value of peas for broiler hickens: An evaluation of micronization and dehulling processes. Poultry Science, Blacksburg, v.75, n.10, p.1243-1252. 1996.

Ketshajwang, K.K.; Holmback, J.; Yeboah, S.O. Quality and compositional studies of some edible leguminosae seed oils in Botswana. Journal of the American Oil Chemists Society, Champing, v.75, n.6, p.741-743, 1998.

Korte, R. Heat resistance of phytohaemagglutinins in weaning food mixtures containing beans (Phaseolus vulgaris). Ecology and Food Nutrition, Massachusetts, v.1, n.2, p.303307, 1972.

Liener, I.E. Implication of antinutritional components in soybean foods. Critical Reviews in Food Science and Nutrition, Boca Raton, v.34, p.31-67, 1994.

Matos, F.J.A., Introdução à fitoquímica experimental. Fortaleza: UFC, 1988. 128p.

Matos, F.J.A.; Alencar, J.W.; Craveiro, A.A.; Machado, N.I.L. Ácidos graxos de algumas oleaginosas tropicais em ocorrência no Nordeste do Brasil. Química Nova, São Paulo, v.15, n.3, p.181-185, 1992. 
McCredy, R.M.; Guggols, J.; Silviera, V.; Wens, H.S. Determination of starch and amylase in vegetables Application to peas. Analytical Chemistry, Washington, v.22, n.9, p.1156-1158, 1950.

Milner, M. Nutritional improvement of food legumes by breeding. 1.ed. London: Wiley- Interscience, 1972.399p.

Mohan, V.R.; Janadhajan, K. Chemical and nutritional evaluation of two germoplasms of the tribal pulse, Bauhinia recemosa Lamk. Plant Foods for Human Nutrition, Spring, v.46, n.4, p.367-374, 1994.

Moreira, R.A.; Perrone, J.C. Purification and partial caracterization of a lectin from Phaseolus vulgaris. Plant Physiology, Maryland, v.59, n.5, p.783-787, 1977.

Nelson, N.A. Aphotometric adaptation of the somogy method for the determination of glucose. Journal of Biology and Chemistry, Baltimore, v.153, n.1, p.375-380, 1944.

Osborne, T.B. The vegetable proteins. 2.ed. London: Longmans Green and Company, 1924.154p.
Peñate, M.A.; Hernández, A.B.; Díaz, E.S.; Fernadéz, I.F.; Triana, M.H.; Maury, C.P.; Boloy, I.L. Evaluacion nutricional de las semillas de Ipil-Ipil (Leucaena leucocephala), casco de vaca (Bauhinia monandra) y Algarrobo de Olor (Albizia lebbeck). Archivos Latinoamericanos Nutricion, Havana, v.38, n.4, p.956-964, 1988.

Rajaram, N.; Janardhajan, K. Chemical composition and nutricional potential of the tribal pulses Bauhinia purpurea, B.racemosa and B.vahlii. Journal of Science Food Agriculture, London, v.55, n.3, p.423-431, 1991.

Silva, D.J. Análise de alimentos (Métodos químicos e biológicos). 2.ed. Viçosa: UFV. Imprensa Universitária, 1990. 195p.

Sousa, F.A.M. Comparação quimiotaxonômica entre espécies da tribo Dalbergiaea e purificação parcial da lectina de sementes de Machaerium acutifolium Vog. Fortaleza: UFC, 1997. 96p. Dissertação Mestrado

Triebold, H.O. Quantitative analysis with applications to agricultural and food products. New York: Van Nortrand Company,1946.331p.

van Kempen, G.J.M. Antinutritional factors in animal feed ingredients. Feed Mix, Doetinchem, v.1, n.1, p.6-11. 1993. 